\title{
Decision Making for Project Appraisal in Uncertain Environments: A Fuzzy-Possibilistic Approach of the Expanded NPV Method
}

\author{
Konstantinos A. Chrysafis and Basil K. Papadopoulos *D
}

check for

updates

Citation: Chrysafis, K.A.;

Papadopoulos, B.K. Decision Making for Project Appraisal in Uncertain

Environments: A Fuzzy-Possibilistic Approach of the Expanded NPV Method. Symmetry 2021, 13, 27. https://doi.org/10.3390/sym 13010027

Received: 12 December 2020 Accepted: 22 December 2020 Published: 25 December 2020

Publisher's Note: MDPI stays neutral with regard to jurisdictional clai$\mathrm{ms}$ in published maps and institutional affiliations.

Copyright: () 2020 by the authors. Licensee MDPI, Basel, Switzerland. This article is an open access article distributed under the terms and conditions of the Creative Commons Attribution (CC BY) license (https:// creativecommons.org/licenses/by/ $4.0 /)$.
Section of Mathematics and Management, Department of Civil Engineering, School of Engineering, Democritus University of Thrace, 67100 Xanthi, Greece; kchrysaf@civil.duth.gr or kgoldenfme@gmail.com

* Correspondence: papadob@civil.duth.gr; Tel.: +30-25410-79747

Abstract: The major drawback of the classic approaches for project appraisal is the lack of the possibility to handle change requests during the project's life cycle. This fact incorporates the concept of uncertainty in the estimation of this investment's worth. To resolve this issue, the authors use fuzzy numbers, possibilistic moments of fuzzy numbers and the hybrid (fuzzy statistic) fuzzy estimators' method in order to introduce a fuzzy possibilistic version of the expanded net present value method (FPeNPV). This approach consists of two factors: the fuzzy possibilistic NPV and the fuzzy option premium. For the estimation of the fuzzy NPV, some basic assumptions are taken into consideration: (1) the opportunity cost of capital, used as the present value interest factor calculated through the weighted average cost of capital (WACC), (2) the equity cost, determined through the possibilistic set-up of the capital asset pricing model CAPM, and (3) the inflation factor, also included in the estimation of the NPV. The fuzzy estimators' method is used for the computation of the fuzzy option premium. An algorithm of nine major steps leads to the computation of the FPeNPV. This gives the administration the opportunity to adapt to potential changes in the company's internal and external environments. In this way, the symmetry between the planning and execution phase of a project can be reinstated. The results validate the statement that fuzzy and intelligent methods remain valuable tools to express uncertainty in various scientific areas. Finally, an illustrative example aims at a thorough comprehension of this new approach of the expanded NPV method.

Keywords: project appraisal; expanded NPV method; fuzzy sets; possibilistic moments; fuzzy volatility; fuzzy binomial model

\section{Introduction}

The main concern for decision-making in project appraisal is the comparison between the future income and the initial cost. The net present value method approximates this challenge by forming a project portfolio that offers the maximum possible net present value (NPV) [1]. Regarding project appraisal, the NPV and discounted cash flows (DCF) methods do not provide project managers with the possibility of decisions made during the project's life. The asymmetry (caused in uncertain environments) between the planning and executing phase in the project's life cycle can be captured by incorporating the expanded NPV (eNPV) method. The expanded NPV employs the option price for more accurate evaluation of real investments (projects).

Stochastic calculus models randomness, and the fuzzy sets theory models uncertainty. Project appraisal includes both stochastic and fuzzy parameters. A future cash flow depends on determinants that can be handled either as a fuzzy or random factor. This statement constitutes the main motivation for the inclusion of fuzzy modeling in project appraisal. The present research effort tackles the vague issue of project appraisal by employing the fuzzy version of the NPV method. Fuzzy sets constitute a reliable mathematical tool to model uncertainty and vagueness in fields such as engineering and finance [2]. 
Fuzzy and intelligent methods present great implementation in investment analysis and decision-making [3-13]. Possibility theory is also a popular mathematical tool for modeling uncertainty in these scientific areas $[14,15]$.

Carlsson and Fuller [16] used fuzzy trapezoidal numbers to represent both the cash inflows and outflows. In [17,18], Muzzioli and Reynaerts used fuzzy sets and possibility theory to model the stock volatility of an option in a binomial model. Kahraman and Kaya [19] introduced fuzzy parameters into stochastic investment analysis and applied probability theory for fuzzy concepts. Collan et al. [20] used fuzzy numbers and possibility theory to price real options and handle existing uncertainty. Tsao [21] derived the NPV in an uncertain environment through pragmatic algorithms.

Chrysafis and Papadopoulos [22] made a research effort to improve the fuzzy version of the program evaluation and review technique PERT and avoid the backward recursion problem. The tools for this operation were the possibilistic moments of fuzzy numbers. Chatterjee et al. [23] presented an alternative approach for the analytical network process (ANP) methodology concerning D numbers in order to manage three types of information: complete, uncertain and incomplete. Dahooie et al. [24] used fuzziness to reinstate symmetry between sustainable development, environmental impact and human well-being. Gebrehiwet et al. [25] assessed the lag times' risks in different life cycles of construction projects using the technique for order of preference by similarity to ideal solution TOPSIS and fuzzy comprehensive evaluation. Lesniak et al. [26] used the fuzzy analytic hierarchy process (FAHP) to increase the validity of contractors' bidding decisions. Rola and Kuchta [27] found a method to estimate the product backlog items of scrum-based information technology IT projects by using fuzzy numbers and strict rules that took into account the human factor. Bolos et al. [28] formed a fuzzy tool for management decisions concerning capital budgeting. Chrysafis et al. [29] used fuzzy tools and techniques for the selection of fuel suppliers and optimal bunkering contracts. Abidin et al. [30] proposed an alternative fuzzy clustering method via fuzzy inference systems for the assessment of stock performance for different kinds of investors. Plebankiewicz and Wieczorek [31] used Mamadani's fuzzy inference model to create a cost overrun risk prediction model. Lyczkowska-Hanćkowiak [32] used fuzzy numbers to compute major investment value determinants.

In this paper, the authors propose an alternative methodology for real investment appraisal (i.e., project valuation), taking into consideration multiple factors and increasing flexibility for new decisions in the execution phase of the project. The traditional NPV criterion is modified so that it can handle the uncertain and vague environment existing in investments analysis. In this approach, the discount rate is modeled via the possibilistic set-up of CAPM-resulting from fuzzy data-taking advantage of this method's merits. Then, based on Zadeh's [33,34] extension principle, the NPV equation takes a fuzzy form. Inflation impact is also taken into account. The NPV formula is appropriately modified so that consistency is ensured. The inflation impact is calculated for both the cash flows and for the interest rates, both in real and nominal values. The results of these modifications are different formulas for converting fuzzy nominals to fuzzy real values and vice versa. Finally, the derivation of the call option price (option to expand) leads to the fuzzy possibilistic expanded net present value (FPeNPV) calculation.

\section{Methods}

\subsection{Fuzzy Sets Principles}

Klir and Yuan [35] presented the following definitions and propositions, which are necessary for this study:

Definition 1. Let $X$ be the universal set. If $A$ is a function from $X$ into the interval $[0,1]$, then $A$ is called a fuzzy set or a fuzzy subset of $X . A(x)$ is interpreted as the membership degree of $x$ in the fuzzy set $A$. 
Definition 2. If $A$ is a fuzzy set, by $a$-cuts, $a \in[0,1]$, we mean the sets $A[a]=$ $\{x \in X: A(x) \geq a\}$. It is known that the $a-c u t s$ determine the fuzzy set $A$. The $a-c u t s$ of $A$ are closed intervals. If $A[a]=B[a], \forall a \in[0,1]$ for arbitrary fuzzy sets $A$ and $B$, then it holds that $A=B$.

Definition 3. We say that $A$ is a fuzzy number if the following conditions hold:

1. The fuzzy set $A$ is normalized;

2. The fuzzy set $A$ is convex;

3. The fuzzy set $A$ is upper semi-continuous;

4. The support of $A$ is compact;

5. The fuzzy set $A$ is normalized if there exists $x \in X$, such that $A(x)=1$;

6. The fuzzy set $A$ is a convex fuzzy set if $\forall t \in[0,1]$ and $x_{1}, x_{2} \in X, A\left(t x_{1}+(1-t) x_{2}\right) \geq$ $\min \left\{A\left(x_{1}\right), A\left(x_{2}\right)\right\}$;

7. The supp $(A)=\cup_{a \in(0,1]} A[a]=\{x: A(x)>0\}$.

Definition 4. The membership function of a fuzzy number A can be expressed as

$$
A(x)=\left\{\begin{array}{cc}
0 & \text { for } x \leq a_{1} \\
A_{L}(x) & \text { for } a_{1}<x<a_{2} \\
A_{R}(x) & \text { for } a_{2} \leq x<a_{3} \\
0 & \text { for } x \geq a_{3}
\end{array}\right.
$$

where $A_{L}:\left[a_{1}, a_{2}\right] \rightarrow[0,1]$ and $A_{R}:\left[a_{3}, a_{4}\right] \rightarrow[0,1]$ are the left and right membership functions of the fuzzy number A. Zadeh [33,34], through the extension principle, extended the classical operations between real numbers to their fuzzy counterparts.

Definition 5. In the extension principle, any given function $f: X \rightarrow Y$ induces two functions, $f: F(X) \rightarrow F(Y)$ and $f^{-1}: F(X) \rightarrow F(Y)$, which are defined by $[f(A)](y):$ sup $A(x)$ for all $A \in F(Y)$ and $\left[f^{-1}(B)\right](x): B(f(x))$ for all $B \in F(Y)$. $x / y=f(x)$

Based on the extension principle, any crisp function can be fuzzified (Filev and Yager 1997).

\subsection{Fuzzy Arithmetic}

Klir and Yuan [35] gave the fundamentals of fuzzy arithmetic, which is based on two properties of fuzzy numbers:

Property 1. Each fuzzy set, and thus also each fuzzy number, can fully and uniquely be represented by its a-cuts.

Property 2. The a-cuts of each fuzzy number are closed intervals of real numbers for all $a \in(0,1]$.

These properties enable us to define arithmetic operations on fuzzy numbers, in terms of arithmetic operations, on their a-cuts. The latter operations are a subject of interval analysis. Let $\otimes$ denote any of the four arithmetic operations on closed intervals: addition + , subtraction-, multiplication, and division/. In this case, it can be said that the following is a general property of all arithmetic operations on closed intervals:

$$
[a, b] \otimes[d, e]=[f \otimes g \mid a \leq f \leq b, d \leq g \leq e]
$$

The exception to this is that $[a, b] /[d, e]$ is not defined when $0 \in[d, e]$. That is, the result of an arithmetic operation on closed intervals is again a closed interval. The four arithmetic operations on closed intervals are defined as follows: 


$$
\begin{aligned}
& {[a, b]+[d, e]=[a+d, b+e]} \\
& {[a, b]-[d, e]=[a-e, b-d]} \\
& {[a, b] *[d, e]=[\min \{a d, a e, b d, b e\}, \max \{a d, a e, b d, b e\}] \text { provided that }} \\
& 0 \notin[d, e] \text { If } a, b, c, d>0 \text { then }[a, b] \cdot[c, d]=[a c, b d] \\
& {[a, b] /[d, e]=[a, b] *[1 / d, 1 / e]=[\min \{a / d, a / e, b / d, b / e\}, \max \{a / d, a / e, b / d, b / e\}]} \\
& \text { provided that } 0 \notin[d, e]
\end{aligned}
$$

Note that a real number $\mathrm{r}$ may also be regarded as a special (degenerate) interval $[r, r]$. When one of the above intervals is degenerate, we obtain special operations. When both of them are degenerate, we obtain the standard arithmetic of real numbers.

\subsection{Non-Asymptotic Fuzzy Estimators}

Sfiris and Papadopoulos [36] proved the next two propositions:

Proposition 1. Let $X_{1}, X_{2}, \ldots, X_{n}$ be a random sample, and let $x_{1}, x_{2}, \ldots, x_{n}$ be the sample values assumed by the sample. Additionally, let us say that $\gamma \in(0.1)$ if the size is small. In that case, then

$$
\sigma_{\gamma}^{2}=\left\{\begin{array}{l}
\frac{2-\gamma}{1-\gamma}-\frac{2}{1-\gamma} F\left(\frac{(n-1) s^{2}}{x}\right), \frac{(n-1) s^{2}}{F^{-1}\left(\frac{2-\gamma}{2}\right)} \leq x \leq \frac{(n-1) s^{2}}{M} \\
\frac{2}{1-\gamma} F\left(\frac{(n-1) s^{2}}{x}\right)-\frac{\gamma}{1-\gamma}, \frac{(n-1) s^{2}}{M} \leq x \leq \frac{(n-1) s^{2}}{F^{-1}\left(\frac{\gamma}{2}\right)} \\
0, \text { otherwise }
\end{array}\right.
$$

This is the membership function of a fuzzy number, the support of which is exactly the $(1-\gamma) 100 \%$ confidence interval for $\sigma^{2}$, and the a-cuts of this fuzzy number are the closed intervals:

$$
\sigma_{\gamma}^{2}=V_{\gamma o}[a]=\left[V_{o}^{l}(a), V_{o}^{r}(a)\right]=\left[\frac{(n-1) s^{2}(\gamma)}{\chi_{n-1 ; h(a)}^{2}}, \frac{(n-1) s^{2}(\gamma)}{\chi_{n-1 ; 1-h(a)}^{2}}\right], \forall a \in(0,1]
$$

where $x_{n-1}^{2}$ is the value of the chi-squared distribution with $k=n-1$ degrees of freedom, $x_{n-1, h(a)}^{2}=$ $F^{-1}(1-h(a)), h(a)=(1 / 2-\gamma / 2) \alpha+\gamma / 2$ and $F$ denotes the cumulative distribution function of the chi-squared distribution.

Proposition 2. Let $X_{1}, X_{2}, \ldots, X_{n}$ be a random sample, and let $x_{1}, x_{2}, \ldots, x_{n}$ be sample values assumed by the sample. Additionally, let us say that $\gamma \in(0.1)$ if the size is large. In that case, then

$$
\sigma_{\gamma}^{2}=\left\{\begin{array}{l}
\frac{2-\gamma}{1-\gamma}-\frac{2}{1-\gamma} \Phi\left(\sqrt{(n-1) / 2}\left(s^{2} / x-1\right)\right), \frac{s^{2}}{1+\Phi^{-1}\left(1-\frac{\gamma}{2}\right) \sqrt{2 /(n-1)}} \leq x \leq s^{2} \\
\frac{2-\gamma}{1-\gamma}-\frac{2}{1-\gamma} \Phi\left(\sqrt{(n-1) / 2}\left(-s^{2} / x+1\right)\right), s^{2} \leq x \leq \frac{s^{2}}{1-\Phi^{-1}\left(1-\frac{\gamma}{2}\right) \sqrt{2 /(n-1)}} \\
0, \text { otherwise }
\end{array}\right.
$$

This is the membership function of a fuzzy number, the support of which is exactly the $(1-\gamma) 100 \%$ confidence interval for $\sigma^{2}$, and the a-cuts of this fuzzy number are the closed intervals:

$$
\sigma_{\gamma}^{2}[\alpha]=V_{\gamma}[a]=\left[V_{\gamma c}^{l}(a), V_{\gamma}^{r}(a)\right]=\left[\frac{s^{2}(\gamma)}{1+z_{h(a)} \sqrt{2 /(n-1)}}, \frac{s^{2}(\gamma)}{1-z_{h(a)} \sqrt{2 /(n-1)}}\right], \forall a \in(0,1]
$$

where $Z_{h(a)}=\Phi^{-1}(1-h(a)), h(a)=(1 / 2-\gamma / 2) \alpha+\gamma / 2$ and $\Phi$ denotes the cumulative distribution function of the standard normal distribution. 


\section{Assumprions for the Present Research Work}

\subsection{NPV Formulas}

The net present value is the monetary project's profit or loss. It can be calculated through the discount of the cash inflows and outflows [1]:

$$
N P V=\sum_{i=0}^{T}\left(C I F_{t}-T_{C O F}\right)(1+r)^{-t}
$$

The difference of $C I F_{t}-C O F_{t}$ is the net cash flow (NCF).

The cash flows are subdivided into the initial investment outlay, liquidation value (after the project's closing phase), cash inflows and outflows. Then, the above formula can be reformed as the following:

$$
N P V==-I_{0}+\sum_{i=0}^{T}\left(\left(p_{t}-c o f_{t}\right) x_{t}-C O F_{t}\right)(1+r)^{-t}+L_{t}(1+r)^{-t}
$$

To incorporate inflation in the NPV formulae, the following must happen:

- The real cash flows have to be converted to nominal cash flows (the use of a nominal discount rate is also necessary);

- The cash flows are estimated in real values (the use of a real discount rate is also necessary).

The relationships between the real and nominal values at time $t$ are as follows:

$$
\text { Nominal Cash }(\mathrm{t})=(1+\text { Inflation Rate })^{\mathrm{t}} \times \text { Real Cash flows }
$$

Additionally,

$$
\text { Nominal Discount Rate }=(1+\text { Inflation Rate }) \times(1+\text { Real Discount Rate })-1
$$

Next, the basic assumptions for the conduct of this research work are presented:

- The time value of money is represented by the opportunity cost of capital, calculated through the weighted average cost of capital (WACC);

- The equity cost is determined through the possibilistic set-up of CAPM;

- The inflation factor is also included in the estimation of the NPV;

- The equation for the NPV is fuzzified by considering Zadeh's $[33,34]$ extension principle;

- The value from the expansion of the project is calculated through the fuzzy binomial model.

The formula for the expanded NPV is the following [1]:

$$
\text { Expanded (strategic) NPV = Static (passive) NPV + Option premium }
$$

\subsection{Possibilistic Discount Rate via Possibilistic CAPM}

Chrysafis [37] derived a possibilistic CAPM beta value and a possibilistic value for the market premium. These values lead to a possibilistic set-up of CAPM and to the computation of the after tax weighted average cost of capital (WACC). The possibilistic CAPM beta is

$$
\begin{aligned}
& \text { beta }_{\text {poss }}= \\
& \frac{\int_{0}^{1} a\left(\left(\frac{D_{t}^{r}(a)+P_{t}^{t}(a)}{P_{t-1}^{l}(a)}-1\right)-\left(\frac{D_{t}^{l}(a)+P_{t}^{l}(a)}{P_{t-1}^{+}(a)}-1\right)\right)\left(\left(\frac{d_{t}^{r}(a)+I_{t}^{r}(a)}{I_{t-1}^{l}(a)}-1\right)-\left(\frac{d_{t}^{l}(a)+I_{t}^{l}(a)}{I_{t-1}^{r}(a)}-1\right)\right) d a}{\int_{0}^{1} a\left(\left(\frac{d_{t}^{r}(a)+I_{t}^{r}(a)}{I_{t-1}^{l}(a)}-1\right)-\left(\frac{d_{t}^{l}(a)+I_{t}^{l}(a)}{I_{t-1}^{r}(a)}-1\right)\right)^{2} d a}
\end{aligned}
$$


The possibilistic value for the market risk premium is

$$
R_{M}=\int_{0}^{1} a\left(\left(\frac{D_{t}^{r}(a)+I_{t}^{r}(a)}{I_{t-1}^{l}(a)}-1\right)+\left(\frac{d_{t}^{l}(a)+I_{t}^{l}(a)}{I_{t-1}^{r}(a)}-1\right)\right) d a-R_{f}
$$

The possibilistic value for the equity cost rposs via the possibilistic set-up of CAPM is

$$
\begin{aligned}
& r_{E}= \\
& R_{f} \\
& +\frac{\int_{0}^{1} a\left(\left(\frac{D_{t}^{r}(a)+P_{t}^{t}(a)}{P_{t-1}^{l}(a)}-1\right)-\left(\frac{D_{t}^{l}(a)+P_{t}^{l}(a)}{P_{t-1}^{r}(a)}-1\right)\right)\left(\left(\frac{d_{t}^{r}(a)+I_{t}^{r}(a)}{I_{t-1}^{l}(a)}-1\right)-\left(\frac{d_{t}^{l}(a)+I_{t}^{l}(a)}{I_{t-1}^{r}(a)}-1\right)\right) d a}{\int_{0}^{1} a\left(\left(\frac{d_{t}^{r}(a)+I_{t}^{r}(a)}{I_{t-1}^{l}(a)}-1\right)-\left(\frac{d_{t}^{l}(a)+I_{t}^{l}(a)}{I_{t-1}^{r}(a)}-1\right)\right) d a} \\
& \times \quad\left(\int_{0}^{1} a\left(\left(\frac{D_{t}^{r}(a)+I_{t}^{r}(a)}{I_{t-1}^{l}(a)}-1\right)+\left(\frac{d_{t}^{l}(a)+I_{t}^{l}(a)}{I_{t-1}^{r}(a)}-1\right)\right) d a-R_{f}\right)
\end{aligned}
$$

The appropriate cost of capital to be applied in the project results from after the tax weighted average cost of capital (WACC) is

$$
\mathrm{WACC}=\mathrm{rD}(1-\mathrm{TC}) \mathrm{DA} / \mathrm{V}+\mathrm{rEEA} / \mathrm{V}=\text { rposs }
$$

where $\mathrm{rD}$ is the expected rate on return on debt and $\mathrm{rE}$ is the expected rate of return on equity; in other words, these are the debt cost and the equity cost. The weights DA/V and $\mathrm{EA} / \mathrm{V}$ are the fractions of debt and equity, based on market values. $\mathrm{V}$, the total market value of the firm, is the sum of DA and EA. TC is the corporate tax rate. $r_{D}$ is considered to be the gross redemption yield (GRY\%) [37]. See Abbreviations for the basic notation.

\section{Fuzzy Possibilistic Net Present Value}

Taking into account the equations for the NPV (Equations (1) and (2)), the adjustment to inflation and the assumptions presented above, the definitions for certain approaches of the FPNPV are derived:

Definition 6. A project's fuzzy possibilistic NPV, with the fuzzy numbers for $C I F_{t}$ and $C O F_{t}$ and the possibilistic rate resulting from fuzzy data for the discount rate $r_{p o s s}$, is defined as

$$
\begin{aligned}
& F P N P V=-I_{0} \\
& +\sum_{i=1}^{T}\left[\left(\operatorname{CIF}_{t}^{l}(a)-\operatorname{TCOF}_{t}^{r}(a)\right)\left(1+r_{\text {poss }}\right)^{-t},\left(\operatorname{CIF}_{t}^{r}(a)-\operatorname{TCOF}_{t}^{l}(a)\right)\left(1+r_{\text {poss }}\right)^{-t}\right]
\end{aligned}
$$

This is eexpressed in a-cuts form. See Appendix A for the operations.

Definition 7. The conversion of a project's fuzzy possibilistic NPV from real to nominal values, with the fuzzy numbers for $C I F_{t}, C O F_{t}$ and $f_{t}$ and the possibilistic rate resulting from the fuzzy data for the discount rate $r_{\text {poss }}$, is defined as

$$
\begin{aligned}
& \text { FPNPV }=-I_{0} \\
& +\sum_{i=1}^{T}\left(\begin{array}{c}
\left(\left[\operatorname{CIF}_{t}^{l}(a)-\operatorname{TCOF}_{t}^{r}(a), \operatorname{CIF}_{t}^{l}(a)-\operatorname{TCOF}_{t}^{l}(a)\right]\right) \\
{\left[1+f_{t}^{l}(a), 1+f_{t}^{r}(a)\right]^{t}\left[1+\frac{r_{\text {poss }}-f_{t}^{r}(a)}{1+f_{t}^{r}(a)}, 1+\frac{r_{\text {poss }}-f_{t}^{l}(a)}{1+f_{t}^{l}(a)}\right]}
\end{array}\right)
\end{aligned}
$$

Next, the operation of multiplication on intervals is applied, depending on the sign of the operation $\operatorname{CIF}_{t}[a]-\operatorname{TCOF}_{t}[a]$ (expressed in a-cuts form). See Appendix A for the operations. 
Definition 8. The conversion of a project's fuzzy possibilistic NPV from nominal to real values, with the fuzzy numbers for $C I F_{t}, C O F_{t}$ and $f_{t}$ and the possibilistic rate resulting from the fuzzy data for the discount rate $r_{\text {poss }}$, is defined as

$$
\begin{aligned}
& \text { FPNPV }=-I_{0} \\
& +\sum_{i=1}^{T}\left(\begin{array}{l}
{\left[\operatorname{CIF}_{t}^{l}(a)-\operatorname{TCOF}_{t}^{r}(a), \operatorname{CIF}_{t}^{l}(a)-\operatorname{TCOF}_{t}^{l}(a)\right]} \\
{\left[\left(1+f_{t}^{l}(a)\right)^{t},\left(1+f_{t}^{r}(a)\right)^{t}\right]} \\
{\left[\left(1+r_{\text {poss }}+f_{t}^{r}(a)+r_{\text {poss }} f_{t}^{r}(a)\right)^{-t},\left(1+r_{\text {poss }}+f_{t}^{l}(a)+r_{\text {poss }} f_{t}^{l}(a)\right)^{-t}\right]}
\end{array}\right)
\end{aligned}
$$

Next, the operation of multiplication on intervals is applied, depending on the sign of the operation CIF $[a]$ - TCOF $[$ a $]$ (expressed in a-cuts form). See Appendix A for the operations.

Definition 9. A project's fuzzy possibilistic NPV, with the fuzzy numbers for $p_{t}, \operatorname{cof}_{t}, x_{t}, C O F_{t}, f_{t}$ and $L$ and the possibilistic rate resulting from the fuzzy data for the discount rate $r_{\text {poss, }}$ is defined as FPNPV $=-I_{0}$

$$
+\sum_{i=1}^{T}\left(\begin{array}{l}
\left(\left[\left(p_{t}^{l}(a)-\operatorname{cof} f_{t}^{r}(a)\right) x_{t}^{l}(a)-\operatorname{COF}_{t}^{r}(a),\left(p_{t}^{r}(a)-\operatorname{cof}_{t}^{l}(a)\right) x_{t}^{r}(a)-\operatorname{COF}_{t}^{l}(a)\right]\right) \\
\left(1+r_{\text {poss }}\right)^{-t}+\left[\left(1+r_{\text {poss }}\right)^{-T} L_{t}^{l}(a),\left(1+r_{\text {poss }}\right)^{-T} L_{t}^{r}(a)\right]
\end{array}\right)
$$

Next, the operation of multiplication on intervals is applied, depending on the sign of the calculation $\left(p_{t}[a]-\operatorname{cof} f_{t}[a]\right) x_{t}[a]-\operatorname{COF}_{t}[a]$ (expressed in a-cuts form). See Appendix A for the operations.

Definition 10. The conversion of a project's fuzzy possibilistic NPV from real to nominal values, with the fuzzy numbers for $p_{t}, \operatorname{cof}_{t}, x_{t}, C O F_{t}, f_{t}$ and $L$ and the possibilistic rate resulting from the fuzzy data for the discount rate $r_{\text {poss, }}$ is defined as

$$
\begin{aligned}
& \text { FPNPV }=-I_{0} \\
& +\sum_{i=1}^{T}\left(\begin{array}{l}
{\left[\left(p_{t}^{l}(a)-\operatorname{cof} f_{t}^{r}(a)\right) x_{t}^{l}(a)-\operatorname{COF}_{t}^{r}(a),\left(p_{t}^{r}(a)-\operatorname{cof} f_{t}^{l}(a)\right) x_{t}^{r}(a)-\operatorname{COF}_{t}^{l}(a)\right]} \\
{\left[1+f_{t}^{l}(a), 1+f_{t}^{r}(a)\right]^{t}\left[1+r_{\text {poss }}+f_{t}^{l}(a)+r_{\text {poss }} f_{t}^{l}(a), 1+r_{\text {poss }}+f_{t}^{r}(a)+r_{\text {poss }} f_{t}^{r}(a)\right]^{-t}} \\
+\left[\left[L_{t}^{l}(a), L_{t}^{r}(a)\right]\left[1+f_{t}^{l}(a), 1+f_{t}^{r}(a)\right]\right. \\
{\left[1+r_{\text {poss }}+f_{t}^{l}(a)+r_{\text {poss }} f_{t}^{l}(a), 1+r_{\text {poss }}+f_{t}^{r}(a)+r_{\text {poss }} f_{t}^{r}(a)\right]^{-T}}
\end{array}\right)
\end{aligned}
$$

Next, the operation of multiplication on intervals is applied, depending on the sign of the operation $\left(p_{t}[a]-\operatorname{cof} f_{t}[a]\right) x_{t}[a]-C O F_{t}[a]$ (expressed in a-cuts form). See Appendix A for the operations.

Definition 11. The conversion of a project's fuzzy possibilistic NPV from nominal to real values, with fuzzy numbers for $p_{t}, \operatorname{cof}_{t}, x_{t}, C O F_{t}, f_{t}$ and $L$ and the possibilistic rate resulting from the fuzzy data for the discount rate $r_{\text {poss }}$, is defined as

$$
\begin{aligned}
& \text { FPNPV }=-I_{0} \\
& +\sum_{i=1}^{T}\left(\begin{array}{l}
{\left[\left(p_{t}^{l}(a)-\operatorname{cof} f_{t}^{r}(a)\right) x_{t}^{l}(a)-\operatorname{COF}_{t}^{r}(a),\left(p_{t}^{r}(a)-\operatorname{cof}_{t}^{l}(a)\right) x_{t}^{r}(a)-\operatorname{COF}_{t}^{l}(a)\right]} \\
\left.+\left[L_{t}^{l}(a), L_{t}^{r}(a)\right]\left[1+f_{t}^{r}(a)\right]^{t}\left[1+\frac{r_{\text {poss }}-f_{t}^{r}(a)}{1+f_{t}^{r}(a)}, 1+\frac{r_{\text {poss }}-f_{t}^{l}(a)}{1+f_{t}^{l}(a)}\right]^{l}(a), 1+f_{t}^{r}(a)\right]\left[1+\frac{r_{\text {poss }}-f_{t}^{r}(a)}{1+f_{t}^{r}(a)}, 1+\frac{r_{\text {poss }}-f_{t}^{l}(a)}{1+f_{t}^{l}(a)}\right]^{-T}
\end{array}\right)
\end{aligned}
$$

Next, the operation of multiplication on intervals is applied, depending on the sign of the operation $\left(p_{t}[a]-\operatorname{cof} f_{t}[a]\right) x_{t}[a]-C O F_{t}[a]$ (expressed in a-cuts form). See Appendix A for the operations.

\section{Fuzzy Binomial Model}

\subsection{The Classic Binomial Model}

The methodology for the binomial model was presented by Cox et al. [38]. According to this model, the investment duration is divided into $n$ discrete time intervals. The stock 
price may rise by a multiple of $e_{u}$ (greater than 1) with a probability $p$ or fall by a multiple of $e_{d}$ (less than 1 ) with a probability $q=1-p$.

Next, the equations for the call and option price are presented with the assumption that there are no dividends paid during the investment's life [39]. The call option price can be expressed as

$$
C_{t}=e^{-r f(t)} \sum_{j=0}^{n}{ }^{n} C_{j} p^{j}(1-p)^{n-j} \max \left\{0, S_{t} e^{j u+(n-j) d}-X\right\}
$$

The put option price can be expressed as

$$
P_{t}=e^{-r f(t)} \sum_{j=0}^{n}{ }^{n} C_{j} p^{j}(1-p)^{n-j} \max \left\{0,-S_{t} e^{j u+(n-j) d}+X\right\}
$$

where $C_{t}$ is call option price at time $t, P_{t}$ is the put option price at time $t, j$ is the number of upward jumps, $k-j$ is the number of downward jumps, $S_{t}$ is the cash flow at time $t$ and $\mathrm{X}$ is the strike price.

\subsection{Fuzzy Up and Down Probabilities}

Then, the up and down probabilities are derived. The author applies the algorithm of Muzzioli and Reynaerts [17] for solving fuzzy systems to the financial application of the binomial model by using the continuously compounding discount factor $e^{r f(t)}$ where $f:(0,+\infty) \rightarrow(0,+\infty):$

$$
\left.\begin{array}{c}
p_{u}+p_{d}=1 \\
u p_{u}+d p_{d}=e^{r f(t)}
\end{array}\right\}
$$

To find the solutions of the above system, the following linear programming problem has to be solved:

$$
\max _{u, d}\left(\text { resp. } \min _{u, d}\right) \frac{e^{r f(t)}-d}{u-d} \text { and } \max _{u, d}\left(\text { resp. } \min _{u, d}\right) \frac{u-e^{r f(t)}}{u-d}
$$

where

$$
e^{r f(t)} \leq u^{l}(a) d^{r} \leq e^{r f(t)} e^{r f(t)} \geq 10<d \leq 1 u \geq 1
$$

The first step is the derivation of the following partial derivatives:

1. $\frac{\partial p_{u}}{\partial u}=\frac{d-e^{r f f(t)}}{(u-d)^{2}}<0$

2. $\frac{\partial p_{u}}{\partial d}=\frac{e^{r f(t)}-u}{(u-d)^{2}}<0$

3. $\frac{\partial p_{d}}{\partial u}=\frac{e^{r f(t)}-d}{(u-d)^{2}}>0$

4. $\frac{\partial p_{d}}{\partial d}=\frac{u-e^{r f(t)}}{(u-d)^{2}}>0$

Thus, the maximum of $P_{u}$ is obtained for $u_{\max }=u^{l}(\alpha)\left(\right.$ resp. $\left.d_{\max }=d^{l}(\alpha)\right)$ and the minimum for $u_{\min }=u^{r}(\alpha)$ (resp. $d_{\max }=d^{r}(\alpha)$ ).

Additionally, the maximum of $P_{d}$ is obtained for $u_{\max }=u^{r}(\alpha)$ (resp. $\left.d_{\max }=d^{r}(\alpha)\right)$ and the minimum for $u_{\min }=u^{l}(\alpha)$ (resp. $d_{\max }=d^{l}(\alpha)$ ).

As such, the solution of the system is

$$
\left(\left[\frac{e^{r f(t)}-d^{r}(a)}{u^{r}(a)-d^{r}(a)}, \frac{e^{r f(t)}-d^{l}(a)}{u^{l}(a)-d^{l}(a)}\right],\left[\frac{u^{l}(a)-e^{r f(t)}}{u^{l}(a)-d^{l}(a)}, \frac{u^{r}(a)-e^{r f(t)}}{u^{r}(a)-d^{r}(a)}\right]\right)
$$


Equivalently, it could also be

$$
p_{u}=\left[\frac{e^{r f(t)}-d^{r}(a)}{u^{r}(a)-d^{r}(a)}, \frac{e^{r f(t)}-d^{l}(a)}{u^{l}(a)-d^{l}(a)}\right]
$$

For $p_{d}$, the solution is

$$
p_{d}=\left[\frac{u^{l}(a)-e^{r f(t)}}{u^{l}(a)-d^{l}(a)}, \frac{u^{r}(a)-e^{r f(t)}}{u^{r}(a)-d^{r}(a)}\right]
$$

For the estimation of the up and down jump factors, the original methodology gives the following formulas:

$$
u=e^{\sigma \sqrt{f(t)}} \text { and } d=e^{-\sigma \sqrt{f(t)}}
$$

Under the extension principle, these factors can be fuzzified as the following:

$$
u[a]=\left[u^{l}(a), u^{r}(a)\right]=\left[e^{\sigma_{Y Z}^{l}(a) \sqrt{f(t)}}, e^{\sigma_{Y Z}^{r}(a) \sqrt{f(t)}}\right]
$$

This could also be expressed as

$$
\begin{gathered}
u^{l}(a)=e^{\sigma_{Y Z}^{l}(a) \sqrt{f(t)}} \text { and } u^{r}(a)=e^{\sigma_{Y Z}^{r}(a) \sqrt{f(t)}} \\
d[a]=\left[d^{l}(a), d^{r}(a)\right] \stackrel{\text { relation } x}{=}\left[e^{-\sigma_{Y Z}^{l}(a) \sqrt{f(t)}}, e^{-\sigma_{Y Z}^{r}(a) \sqrt{f(t)}}\right]
\end{gathered}
$$

Additionally, it can be said that

$$
d^{l}(a)=e^{-\sigma_{Y Z}^{l}(a) \sqrt{f(t)}} \text { and } d^{r}(a)=e^{-\sigma_{Y Z}^{r}(a) \sqrt{f(t)}}
$$

where $\sigma_{\curlyvee Z}$, is the fuzzy estimator for the standard deviation of the asset.

\subsection{Fuzzy Volatility}

Yang and Zhang [40] introduced the following estimator for the volatility of the company's stock:

$$
\text { Var }=V_{0}+k V_{C P}+(1-k) V_{R S}
$$

where

$$
\begin{gathered}
V_{o}=\frac{1}{n-1} \sum_{i=1}^{n}\left(o_{i}-\bar{o}\right)^{2} \\
V_{c}=\frac{1}{n-1} \sum_{i=1}^{n}\left(c_{i}-\bar{c}\right)^{2} \\
V_{R S}=\frac{1}{n} \sum_{i=1}^{n}\left[u_{i}\left(u_{i}-c_{i}\right)+d_{i}\left(d_{i}-c_{i}\right)\right]
\end{gathered}
$$

where $T$ is the time interval of each period, $f$ is the fraction of the period (between $[0,1]$ ) when trading is closed, $V$ is the unknown variance, which is the unknown volatility squared $\left(\sigma^{2}\right), C P_{0}$ is the closing price of the previous period (at time 0$), O P_{1}$ is the opening price of the current period (at time $f$ ), $H P_{1}$ is the the current period's high during the trading interval (between $[f, 1]), L P_{1}$ is the current period's low during the trading interval (between $[f, 1]), C P_{1}$ is the closing price of the current period (at time 1), $o=\ln O P_{1}-\ln$ $C P_{0}$, the normalized open, $u=\ln H P_{1}-\ln O P_{1}$, the normalized high, $d=\ln L P_{1}-\ln O P_{1}$, the normalized low, and, $c=\ln C P_{1}-\ln O P_{1}$, the normalized close.

In this research work, the authors employed the fuzzy estimator for $V_{o}$ and $V_{c}$ and finally derived the fuzzy estimator for the Yang and Zhang variance.

Based on Proposition 2, the fuzzy estimators for the variance of each variable for a large sample are as follows. 
The support for the fuzzy membership function for the fuzzy variance of the random sample of $\mathrm{O}_{1}, \mathrm{O}_{2}, \ldots, \mathrm{O}_{\mathrm{n}}$ is exactly the $(1-\gamma) 100 \%$ confidence interval for $\sigma^{2}$, and the a-cuts of this fuzzy number are the closed intervals

$$
V_{o}[a]=\left[V_{o}^{l}(a), V_{o}^{r}(a)\right]=\left[\frac{s^{2}(o)}{1+z_{h(a)} \sqrt{2 /(n-1)}}, \frac{s^{2}(o)}{1-z_{h(a)} \sqrt{2 /(n-1)}}\right], \forall a \in[0,1]
$$

where $Z_{h(a)}, h_{(a)}$ and $\Phi$ have already been defined.

Similarly, the support for the fuzzy membership function for the fuzzy variance of the random sample of $C_{1}, C_{2}, \ldots, C_{n}$ is exactly the $(1-\gamma) 100 \%$ confidence interval for $\sigma^{2}$, and the a-cuts of this fuzzy number are the closed intervals

$$
V_{c}[a]=\left[V_{c}^{l}(a), V_{c}^{r}(a)\right]=\left[\frac{s^{2}(c)}{1+z_{h(a)} \sqrt{2 /(n-1)}}, \frac{s^{2}(c)}{1-z_{h(a)} \sqrt{2 /(n-1)}}\right], \forall a \in[0,1]
$$

where $Z_{h(a)}, h_{(a)}$ and $\Phi$ have already been defined.

Based on Proposition 1, the fuzzy estimators for the variance of each variable for a small sample are as follows.

The support for the fuzzy membership function for the fuzzy variance of the random sample of $O_{1}, O_{2}, \ldots, O_{n}$ is exactly the $(1-\gamma) 100 \%$ confidence interval for $\sigma^{2}$, and the a-cuts of this fuzzy number are the closed intervals

$$
V_{o}[a]=\left[V_{o}^{l}(a), V_{o}^{r}(a)\right]=\left[\frac{(n-1) s^{2}(o)}{\chi_{n-1 ; h(a)}^{2}}, \frac{(n-1) s^{2}(o)}{\chi_{n-1 ; 1-h(a)}^{2}}\right], \forall a \in[0,1]
$$

where $Z_{h(a)}, h_{(a)}$ and $\Phi$ have already been defined.

Similarly, the support for the fuzzy membership function for the fuzzy variance of the random sample of $C_{1}, C_{2}, \ldots, C_{n}$ is exactly the $(1-\gamma) 100 \%$ confidence interval for $\sigma^{2}$, and the a-cuts of this fuzzy number are the closed intervals

$$
V_{c}[a]=\left[V_{c}^{l}(a), V_{c}^{r}(a)\right]=\left[\frac{(n-1) s^{2}(c)}{\chi_{n-1 ; h(a)}^{2}}, \frac{(n-1) s^{2}(c)}{\chi_{n-1 ; 1-h(a)}^{2}}\right], \forall a \in[0,1]
$$

where $Z_{h(a)}, h_{(a)}$ and $\Phi$ have already been defined.

In this work, the authors propose a fuzzy version of the constant $k$ in order to include the prices proposed from various experts, as mentioned above. Under the extension principal, the $k$ factor for the minimization of the variance can be fuzzified. That is, it can be expressed as

$$
k_{0}[a]=\frac{\left[\theta^{l}(a), \theta^{r}(a)\right]-1}{\left[\theta^{l}(a), \theta^{r}(a)\right]+\frac{n+1}{n-1}}=\left[\frac{\theta^{l}(a)-1}{\theta^{r}(a)+\frac{n+1}{n-1}}, \frac{\theta^{r}(a)-1}{\theta^{l}(a)+\frac{n+1}{n-1}}\right]
$$

Taking into consideration Equations (19)-(24), the fuzzy estimator for the Yang and Zhang variance derives as follows.

When the sample is large, then 


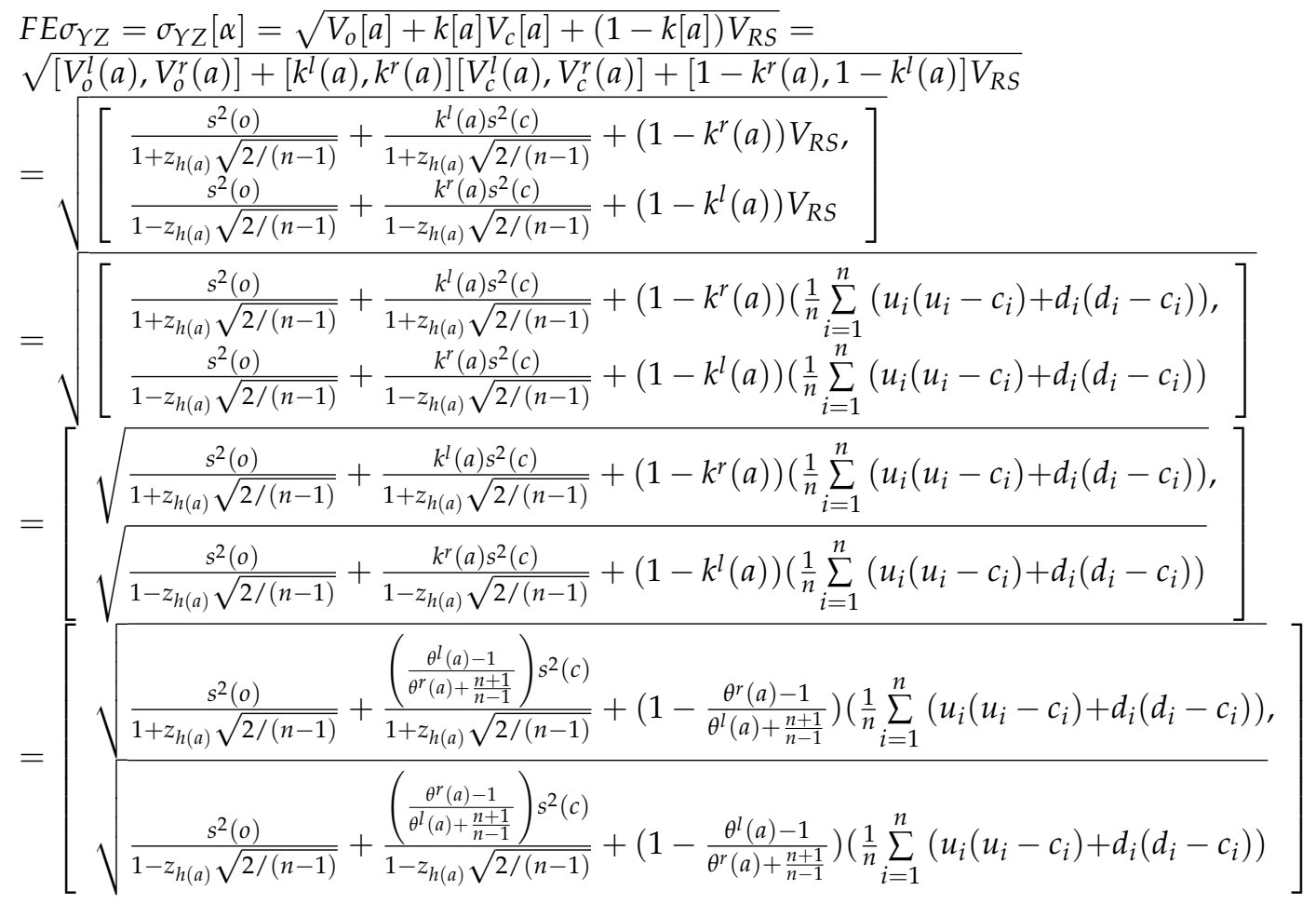

or

$$
\begin{gathered}
\sigma_{Y Z}^{l}(a)=\sqrt{\frac{s^{2}(o)}{1+z_{h(a)} \sqrt{2 /(n-1)}}+\frac{\left(\frac{\theta^{l}(a)-1}{\theta^{r}(a)+\frac{n+1}{n-1}}\right) s^{2}(c)}{1+z_{h(a)} \sqrt{2 /(n-1)}}+\left(1-\frac{\theta^{r}(a)-1}{\theta^{l}(a)+\frac{n+1}{n-1}}\right)\left(\frac{1}{n} \sum_{i=1}^{n}\left(u_{i}\left(u_{i}-c_{i}\right)+d_{i}\left(d_{i}-c_{i}\right)\right),\right.} \\
\sigma_{Y Z}^{r}(a)=\sqrt{\frac{s^{2}(o)}{1-z_{h(a)} \sqrt{2 /(n-1)}}+\frac{\left(\frac{\theta^{l}(a)-1}{\theta^{r}(a)+\frac{n+1}{n-1}}\right) s^{2}(c)}{1-z_{h(a)} \sqrt{2 /(n-1)}}+\left(1-\frac{\theta^{r}(a)-1}{\theta^{l}(a)+\frac{n+1}{n-1}}\right)\left(\frac{1}{n} \sum_{i=1}^{n}\left(u_{i}\left(u_{i}-c_{i}\right)+d_{i}\left(d_{i}-c_{i}\right)\right)\right.}
\end{gathered}
$$

When the sample is small, then 


$$
\begin{aligned}
& F E \sigma_{Y Z}=\sqrt{V_{o}[a]+k[a] V_{c}[a]+(1-k[a]) V_{R S}}= \\
& \sqrt{\left[V_{o}^{l}(a), V_{o}^{r}(a)\right]+\left[k^{l}(a), k^{r}(a)\right]\left[V_{c}^{l}(a), V_{c}^{r}(a)\right]+\left[1-k^{r}(a), 1-k^{l}(a)\right] V_{R S}} \\
& =\sqrt{\left[\begin{array}{l}
\frac{(n-1) s^{2}(o)}{\chi_{n-1 ; h(a)}^{2}}+\frac{k^{l}(a)(n-1) s^{2}(c)}{\chi_{n-1 ; h(a)}^{2}}+\left(1-k^{r}(a)\right) V_{R S} \\
\frac{(n-1) s^{2}(o)}{\chi_{n-1 ; 1-h(a)}^{2}}+\frac{k^{r}(a)(n-1) s^{2}(c)}{\chi_{n-1 ; 1-h(a)}^{2}}+\left(1-k^{l}(a)\right) V_{R S}
\end{array}\right]} \\
& =\sqrt{\left[\begin{array}{l}
\frac{(n-1) s^{2}(o)}{\chi_{n-1 ; h(a)}^{2}}+\frac{k^{l}(a)(n-1) s^{2}(c)}{\chi_{n-1 ; h(a)}^{2}}+\left(1-k^{r}(a)\right)\left(\frac{1}{n} \sum_{i=1}^{n}\left(u_{i}\left(u_{i}-c_{i}\right)+d_{i}\left(d_{i}-c_{i}\right)\right),\right. \\
\frac{(n-1) s^{2}(o)}{\chi_{n-1 ; 1-h(a)}^{2}}+\frac{k^{r}(a)(n-1) s^{2}(c)}{\chi_{n-1 ; 1-h(a)}^{2}}+\left(1-k^{l}(a)\right)\left(\frac{1}{n} \sum_{i=1}^{n}\left(u_{i}\left(u_{i}-c_{i}\right)+d_{i}\left(d_{i}-c_{i}\right)\right)\right.
\end{array}\right]} \\
& =\left[\begin{array}{l}
\sqrt{\frac{(n-1) s^{2}(o)}{\chi_{n-1 ; h(a)}^{2}}+\frac{k^{l}(a)(n-1) s^{2}(c)}{\chi_{n-1 ; h(a)}^{2}}+\left(1-k^{r}(a)\right)\left(\frac{1}{n} \sum_{i=1}^{n}\left(u_{i}\left(u_{i}-c_{i}\right)+d_{i}\left(d_{i}-c_{i}\right)\right)\right.}, \\
\sqrt{\frac{(n-1) s^{2}(o)}{\chi_{n-1 ; 1-h(a)}^{2}}+\frac{k^{r}(a)(n-1) s^{2}(c)}{\chi_{n-1 ; 1-h(a)}^{2}}+\left(1-k^{l}(a)\right)\left(\frac{1}{n} \sum_{i=1}^{n}\left(u_{i}\left(u_{i}-c_{i}\right)+d_{i}\left(d_{i}-c_{i}\right)\right)\right.}
\end{array}\right. \\
& =\left[\begin{array}{l}
\sqrt{\frac{(n-1) s^{2}(o)}{\chi_{n-1 ; h(a)}^{2}}+\frac{\left(\frac{\theta^{l}(a)-1}{\theta^{r}(a)+\frac{n+1}{n-1}}\right)(n-1) s^{2}(c)}{\chi_{n-1 ; h(a)}^{2}}+\left(1-\frac{\theta^{r}(a)-1}{\theta^{l}(a)+\frac{n+1}{n-1}}\right)\left(\frac{1}{n} \sum_{i=1}^{n}\left(u_{i}\left(u_{i}-c_{i}\right)+d_{i}\left(d_{i}-c_{i}\right)\right)\right.} \\
\sqrt{\frac{(n-1) s^{2}(o)}{\chi_{n-1 ; 1-h(a)}^{2}}+\frac{\left(\frac{\theta^{r}(a)-1}{\theta^{l}(a)+\frac{n+1}{n-1}}\right)(n-1) s^{2}(c)}{\chi_{n-1 ; 1-h(a)}^{2}}+\left(1-\frac{\theta^{l}(a)-1}{\theta^{r}(a)+\frac{n+1}{n-1}}\right)\left(\frac{1}{n} \sum_{i=1}^{n}\left(u_{i}\left(u_{i}-c_{i}\right)+d_{i}\left(d_{i}-c_{i}\right)\right)\right.}
\end{array}\right]
\end{aligned}
$$

or

$$
\sigma_{Y Z}^{l}(a)=\sqrt{\frac{(n-1) s^{2}(o)}{\chi_{n-1 ; h(a)}^{2}}+\frac{\left(\frac{\theta^{r}(a)-1}{\theta^{l}(a)+\frac{n+1}{n-1}}\right)(n-1) s^{2}(c)}{\chi_{n-1 ; h(a)}^{2}}+\left(1-\frac{\theta^{l}(a)-1}{\theta^{r}(a)+\frac{n+1}{n-1}}\right)\left(\frac{1}{n} \sum_{i=1}^{n}\left(u_{i}\left(u_{i}-c_{i}\right)+d_{i}\left(d_{i}-c_{i}\right)\right)\right.}
$$

and

$$
\sigma_{Y Z}^{r}(a)=\sqrt{\frac{(n-1) s^{2}(o)}{\chi_{n-1 ; 1-h(a)}^{2}}+\frac{\left(\frac{\theta^{r}(a)-1}{\theta^{l}(a)+\frac{n+1}{n-1}}\right)(n-1) s^{2}(c)}{\chi_{n-1 ; 1-h(a)}^{2}}+\left(1-\frac{\theta^{l}(a)-1}{\theta^{r}(a)+\frac{n+1}{n-1}}\right)\left(\frac{1}{n} \sum_{i=1}^{n}\left(u_{i}\left(u_{i}-c_{i}\right)+d_{i}\left(d_{i}-c_{i}\right)\right)\right.}
$$

Next, an illustrative example is presented for thorough comprehension of the computational steps of the proposed method.

\section{Example (Revisited and Substantially Extended for the Illustration of the FPeNPV Method)}

Let us now consider Company A, with an equity/debt ratio of 5/3. The corporate debt has a gross redemption yield of $10 \%$. The corporate debt is also assumed to be risk-free. The corporate tax rate is $30 \%$. Company A is considering Projects P1, P2 and P3. In the same industry, there is Company B, which runs Project P1, and Company C, which runs Projects P2 and P3. The expert has expressed his opinion (Tables 1-4) for the quantities for the stock return's determinants and for each project data as follows [37]. 
Table 1. Expert oponions in the form of the a-cuts of fuzzy numbers.

\begin{tabular}{cccc}
\hline & Company B & \multicolumn{2}{c}{ Company C } \\
\hline Variable & Project P1 & Project P2 & Project P3 \\
\hline$t[\alpha]$ & {$[2.00,2.50]$} & {$[2.20,2.60]$} & {$[3.00,3.50]$} \\
$P t[\alpha]$ & {$[12.00,14.50]$} & {$[11.00,12.00]$} & {$[14.00,15.00]$} \\
$P t-1[\alpha]$ & {$[11.50,11.50]$} & {$[10.50,12.00]$} & {$[11.70,12.00]$} \\
$d t[\alpha]$ & {$[3.50,4.00]$} & {$[3.50,4.00]$} & {$[3.50,4.00]$} \\
$I t[\alpha]$ & {$[12.00,14.50]$} & {$[12.50,14.50]$} & {$[12.00,14.50]$} \\
$I t-1[\alpha]$ & {$[15.00,15.00]$} & {$[15.00,15.00]$} & {$[15.00,15.00]$} \\
\hline
\end{tabular}

Table 2. Data for Project P1.

\begin{tabular}{|c|c|c|c|}
\hline Type of Variable & Variable & Left Tail of A-Cut & Right Tail of A-Cut \\
\hline Crisp & $I$ & \multicolumn{2}{|c|}{$4000.00 €$} \\
\hline Fuzzy & $p t$ & $15.00 €$ & $15.50 €$ \\
\hline Fuzzy & coft & $6.00 €$ & $6.30 €$ \\
\hline Fuzzy & $x t$ & 1500.00 units & 1800.00 units \\
\hline Fuzzy & COFt & $5000.00 €$ & $5400.00 €$ \\
\hline Fuzzy & $f t$ & $4.00 \%$ & $4.20 \%$ \\
\hline Crisp & economic life $T$ & \multicolumn{2}{|c|}{3 years } \\
\hline Fuzzy & $L t$ & $1000.00 €$ & $1,250,00 €$ \\
\hline
\end{tabular}

Table 3. Data for Project P2.

\begin{tabular}{|c|c|c|c|}
\hline Type of Variable & Variable & Left Tail of A-Cut & Right Tail of A-Cut \\
\hline Crisp & $I$ & \multicolumn{2}{|c|}{$4000.00 €$} \\
\hline Fuzzy & $p t$ & $16.00 €$ & $16.70 €$ \\
\hline Fuzzy & coft & $5.00 €$ & $6.50 €$ \\
\hline Fuzzy & $x t$ & 2000.00 units & 2100.00 units \\
\hline Fuzzy & COFt & $4000.00 €$ & $4300.00 €$ \\
\hline Fuzzy & $f t$ & $4.00 \%$ & $4.20 \%$ \\
\hline Crisp & economic life $T$ & \multicolumn{2}{|c|}{3 years } \\
\hline Fuzzy & Lt & $1100.00 €$ & $1400.00 €$ \\
\hline
\end{tabular}

Table 4. Data for Project P3.

\begin{tabular}{cccc}
\hline Type of Variable & Variable & Left Tail of A-Cut & Right Tail of A-Cut \\
\hline Crisp & $I$ & \multicolumn{3}{c}{$6000.00 €$} \\
Fuzzy & $p t$ & $12.00 €$ & $12.50 €$ \\
Fuzzy & $c o f t$ & $4.00 €$ & $5.00 €$ \\
Fuzzy & $x t$ & 3000.00 units & 3200.00 units \\
Fuzzy & COFt & $4000.00 €$ & $4300.00 €$ \\
Fuzzy & $f t$ & $4.00 \%$ & $4.20 \%$ \\
Crisp & economic life T & & 3 years \\
Fuzzy & Lt & $1200.00 €$ & \\
\end{tabular}

The equity/debt ratio of Company B is $7 / 3$, and for Company $C$ it is $3 / 1$. Company A maintains the same capital structure after the potential implementation of Projects P1, P2 and P3. The variables for the projects are expressed in real values. Let us follow the following algorithm to find the FPeNPV for each project in nominal values.

\section{Step 1.}

Identify a suitable equity beta coming from a company running the project in the same industry. Use Equation (5). 


\begin{tabular}{ccc}
\hline Project P1 & Project P2 & Project P3 \\
\hline equity beta & equity beta & equity beta \\
1.5600 & 1.7423 & 0.9870 \\
\hline
\end{tabular}

Step 2.

Degear the equity beta to the asset beta. Strip out the gearing risk to calculate the asset beta for the project $\left(\beta_{\text {asset }}=E_{B} \times \beta_{\text {equity }} /\left[E_{B}+D_{B} \times\left(1-T_{C}\right)\right]\right)$.

\begin{tabular}{ccc}
\hline Project P1 & Project P2 & Project P3 \\
\hline asset beta & asset beta & asset beta \\
1.2000 & 1.4126 & 0.8003 \\
\hline
\end{tabular}

Step 3.

Regear the asset beta to the equity beta. Re-work the same formula to add back the unique gearing relating to the project $\left(\beta_{\text {equity }}=\left[\mathrm{E}_{\mathrm{A}}+\mathrm{D}_{\mathrm{A}} \times\left(1-\mathrm{T}_{\mathrm{C}}\right)\right] \times \beta_{\text {asset }} / \mathrm{E}_{\mathrm{A}}\right)$.

\begin{tabular}{ccc}
\hline Project P1 & Project P2 & Project P3 \\
\hline equity beta & equity beta & equity beta \\
1.7040 & 2.0060 & 1.1364 \\
\hline
\end{tabular}

Step 4.

Calculate the equity cost via the possibilistic set-up of CAPM. Use Equation (7).

\begin{tabular}{ccc}
\hline Project P1 & Project P2 & Project P3 \\
\hline CAPM equity cost & CAPM equity cost & CAPM equity cost \\
0.0283 & 0.0333 & 0.0189 \\
\hline
\end{tabular}

Step 5.

Find the cost of capital (discount rate) via the WACC. Use Equation (8).

\begin{tabular}{ccc}
\hline Project P1 & Project P2 & Project P3 \\
\hline WACC & WACC & WACC \\
$4.39 \%$ & $4.71 \%$ & $3.80 \%$ \\
\hline
\end{tabular}

\section{Step 6.}

Apply the FPNPV method. To apply the analytical form, choose a definition from Definitions 9-11 (Equations (12)-(14)).

Step 7.

Apply Definition 10 for each project to turn the real values into nominal values (Equation (13). See the results in Table 5 (the aggregate results). Based on the FPNPV criterion, P3 must be chosen. Let us now see what happens if we consider an expansion of P3 for one period with the additional expense for the expansion to be $1000 €$.

Step 8.

Combine Equations (15), (17) and (18) and Equations (24) and (26) to find the value of the option to expand (call option). We considered that we have a small sample formed by expert opinions.

Step 9.

Find the fuzzy possibilistic expanded NPV value by adding the static NPV to the call option value (use Equation (4)).

$$
\text { FPeNPV }=[10.125,32 €, 16.001 .54 €] .
$$


Table 5. Aggregated results for the fuzzy possibilistic net present value (NPV) of each project.

\begin{tabular}{cccc}
\hline \multirow{2}{*}{ Period } & \multicolumn{2}{c}{ Net Cash Flow } \\
\cline { 2 - 4 } & 1 & Right Tail of A-Cut & Left Tail of A-Cut \\
\hline \multirow{2}{*}{ Project P1 } & 2 & $3911.45 €$ & $6159.80 €$ \\
& 3 & $1998.97 €$ & $3134.81 €$ \\
Project P2 & $1045.33 €$ & $1625.05 €$ \\
& 1 & $2955.75 €$ & $6919.67 €$ \\
& 2 & $7423.65 €$ & $10,383.77 €$ \\
Project P3 & 3 & $3748.72 €$ & $5241.33 €$ \\
& FPNPV & $1919.12 €$ & $2678.76 €$ \\
& 1 & $9091.49 €$ & $14,303.87 €$ \\
& 2 & $8471.05 €$ & $11,742.01 €$ \\
& 3 & $4296.05 €$ & $5942.02 €$ \\
& FPNPV & $2208.11 €$ & $3038.73 €$ \\
\end{tabular}

\section{Results}

The traditional NPV criterion was modified so that it could handle the uncertain and vague environment existing in financial markets regarding investments. The possibilistic set-up of CAPM was used for the discount rate. The inflation impact in future cash flows and in the discount rate was included. Different formulas for converting fuzzy nominal to fuzzy real values and vice versa were provided. The fuzzy estimator for the Yang and Zhang variance [40] was appied in the binomial option pricing model. This could be derived either from statistical data (in the case of a large sample) or by expert opinions (when the sample is small). The fuzzy estimators method was employed as a risk aversion measure in the FPeNPV, since it gave the choice of choosing the inteval range (through a-cuts). Finally, the calculation of the call option price (option to expand) led to the FPeNPV.

\section{Discussion}

The initial novelties of this research work are the use of the possibilistic beta and possibilistic CAPM [37] for the computation of the equity cost and the possibilistic set up of the WACC as a discount rate for the expanded FPeNPV. The benefits from these applications are the following: (1) the degearing of equity to asset beta, and then the regearing of the found asset beta to equity beta, is a necessary process to add beta to the unique gearing relating to the project. It is shown that the beta adjusted to the relating project is remarkably different than the initial one (e.g., $\mathrm{P}_{3}=0.987$, and after the process $\mathrm{P}_{3}=1.1364$ ); (2) the use of the possibilistic beta for each project does not require statistical information (historical data), which could be biased, and it is based on expert opinions; and (3) the possibilistic beta is a safe translation of fuzzy information. Expert fuzzy estimates conclude to a possibilistic crisp value for the equity cost (from CAPM), which is incorporated in the calculation of the WACC.

The second novelty of the proposed method is the derivation of fuzzy formulae for the conversion from real to nominal values and vice versa. The proposed method includes the appropriate adjustment to inflation both for the cash flows and for the rate. As one can notice, inflation has a direct impact not only on the cash flows, but also on the rate of return of each project. This adjustment to inflation does not necessarily offer accuracy in the calculation of the expanded FPeNPV, but most probably more realistic interval estimates for the project value.

Another novelty of the proposed method is the use of non-asymptotic fuzzy estimators for the volatility of the binomial model. The fuzzy estimators method for volatility uses a set of confidence intervals, producing fuzzy numbers for the estimation of probability distribution parameters [36]. The fuzzy estimators method acts as risk aversion measure in the expanded FPeNPV, since the financial analyst can decide how close to be to the point estimation. The fuzzy estimator for the variance (that was finally used in the binomial 
option pricing model) can be derived either from statistical data (considering that we have a large sample) or by expert opinions (in the case of a small sample). In this example, we considered a small sample formed by expert opinions.

Finally, the derivation of the call option price (option to expand) leads to the expanded FPeNPV calculation and to its offered merits, as discussed in previous sections. The current expectation is that the cash flows from the investment belong to the interval [8.975.22 $€$, 14.722.,76 $€]$. We find the expanded FPeNPV for the examined scenario belongs to the interval $[10.125,32 €, 16.001 .54 €]$. Thus, the expansion can be chosen.

\section{Conclusions and Further Work}

Intelligent and fuzzy methods remain reliable methods in financial management and investment appraisal. Possibility theory also gives the opportunity to safely translate the fuzzy information. Hybrid methods, such as the fuzzy estimators' method, give the choice of deriving fuzzy information either from statistical data or from expert opinions. The FPeNPV method offers flexibility for future decision-making in investment appraisal.

The contribution of the proposed method, the fuzzy possibilistic expanded net present value (FPeNPV), is the combination of several methods in each step in order to provide the administration with more realistic interval results for a project's value. The main authors' effort is to provide a set of computational steps that improve all the intermediate assumptions and variable estimates until reaching the final goal, which is a realistic and flexible approximation for a project's value. The traditional NPV criterion is modified so that it can handle the uncertain and vague environment existing in financial markets regarding investments. The discount rate is modeled via the possibilistic set-up of CAPMresulting from fuzzy data-taking advantage of this method's merits. Inflation impact is also taken into account. The NPV formula is appropriately modified so that consistency is ensured. The results of these modifications are different formulas for converting fuzzy nominals to fuzzy real values and vice versa. The fuzzy estimator for the Yang and Zhang variance (that was finally used in the binomial option pricing model) can be derived either from statistical data (considering that we have a large sample) or by expert opinions (in the case of a small sample). The fuzzy estimators method acts as a risk aversion measure in the FPeNPV, since the financial analyst can decide how close to be to the point estimation. The derivation of the call option price (option to expand) leads to the FPeNPV calculation.

Due to the incorporation of (1) the possibilistic equity cost (and as a consequence, the possibilistic WACC), (2) the fuzzy NPV adjusted for inflation (both cash flows and rate) and (3) the fuzzy volatility in the call option calculation (in the fuzzy binomial model), the expanded FPeNPV offers results closer to market reality. The limitation of this research work is the assumption that the project's value volatility can be approximated by the company's (running the project) stock volatility. Thus, a direction for future research could be setting the examination of the similarity degree between these two factors. Moreover, the application of this methodology to construction, transition, reform and various types of projects would be of great interest.

Author Contributions: Conceptualization, K.A.C.; methodology, K.A.C.; project administration, B.K.P.; validation, B.K.P.; writing—original draft, K.A.C.; writing-review and editing, B.K.P. All authors have read and agreed to the published version of the manuscript.

Funding: This research received no external funding.

Institutional Review Board Statement: Not applicable.

Informed Consent Statement: Not applicable.

Data Availability Statement: Not applicable.

Acknowledgments: The authors would like to thank the anonymous reviewers for their valuable comments which increased this paper's quality.

Conflicts of Interest: The authors declare no conflict of interest. 


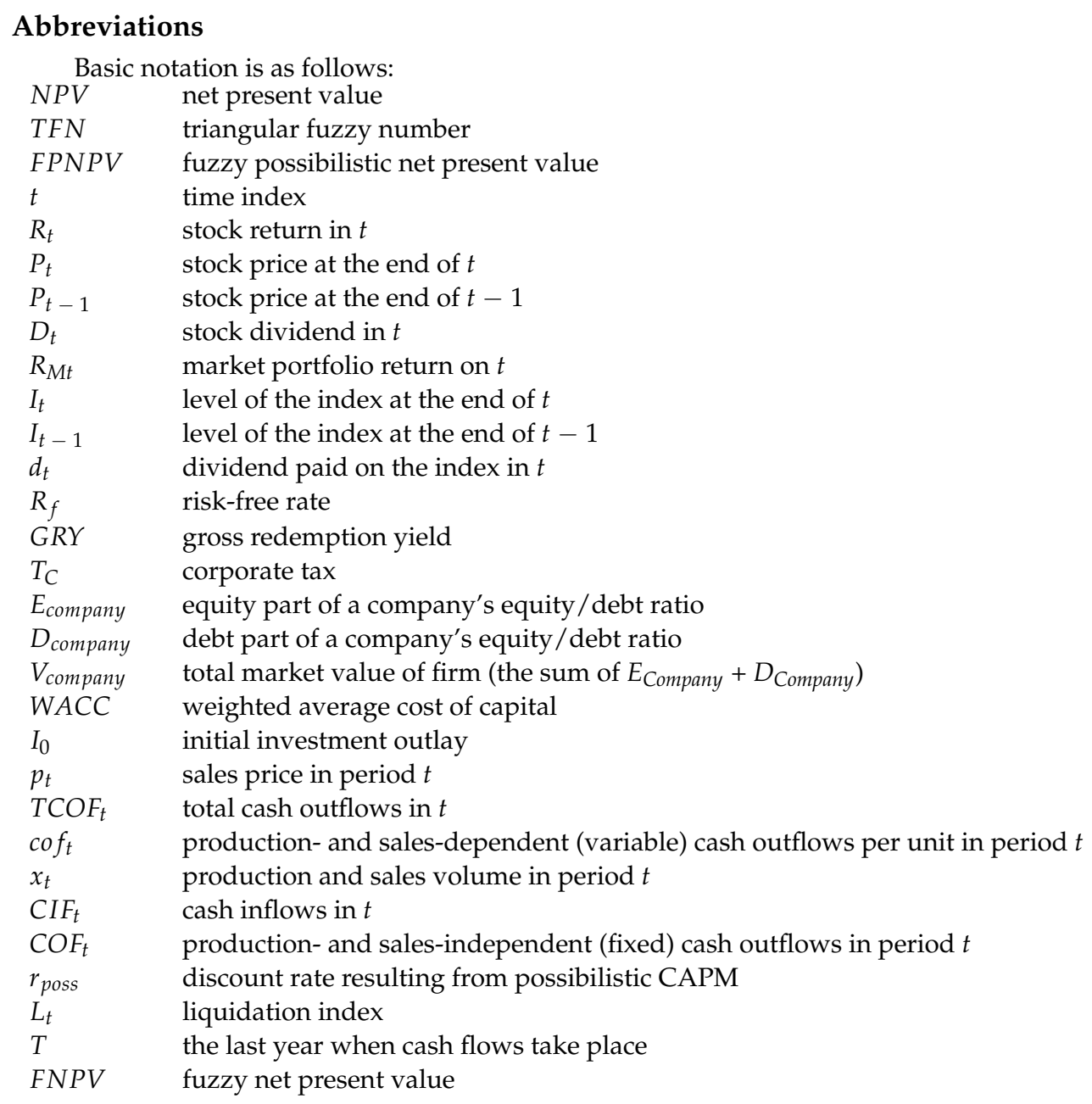

\section{Appendix A}

Operations for Definition 6

No conversion needed

$$
F P N P V=-I_{0}+\sum_{i=1}^{T}\left(C I F_{t}-\text { TCOF }_{t}\right)(1+r)^{-t} \rightarrow
$$

$>$ The extension principle:

$$
\begin{aligned}
& F P N P V=-I_{0} \\
& +\sum_{i=1}^{T}\left(\left[C I F_{t}^{l}(a), \operatorname{CIF}_{t}^{r}(a)\right]-\left[\operatorname{TCOF}_{t}^{l}(a), \operatorname{TCOF}_{t}^{r}(a)\right]\right)\left(1+r_{\text {poss }}\right)^{-t} \rightarrow \\
& \operatorname{FPNPV}=-I_{0} \\
& +\sum_{i=1}^{T}\left[\left(\operatorname{CIF}_{t}^{l}(a)-\operatorname{TCOF}_{t}^{r}(a), \operatorname{CIF}_{t}^{r}-\operatorname{TCOF}_{t}^{l}(a)\right]\left(1+r_{\text {poss }}\right)^{-t}\right. \\
& \quad F P P V=-I_{0} \\
& +\sum_{i=1}^{T}\left[\left(\operatorname{CIF}_{t}^{l}(a)-\operatorname{TCOF}_{t}^{r}(a)\right)\left(1+r_{\text {poss }}\right)^{-t},\left(\operatorname{CIF}_{t}^{r}(a)-\operatorname{TCOF}_{t}^{l}(a)\right)\left(1+r_{\text {poss }}\right)^{-t}\right]
\end{aligned}
$$

Operations for Definition 7

Real to Nominal

- $\quad$ The basic formula:

$$
F P N P V=-I_{0}+\sum_{i=1}^{T}\left(C I F_{t}-\text { TCOF }_{t}\right)(1+r)^{-t} \rightarrow
$$


- Convert the real cash flows and real discount rate to nominal values:

$$
\begin{aligned}
& F P N P V=-I_{0}+\sum_{i=1}^{T}\left(C I F_{t}-\text { TCOF }_{t}\right)(1+f)^{t}((1+r)(1+f))^{-t} \rightarrow \\
& F P N P V=-I_{0}+\sum_{i=1}^{T}\left(C I F_{t}-\text { TCOF }_{t}\right)(1+f)^{t}(1+r+f+r f)^{-t} \rightarrow
\end{aligned}
$$

- The extension principle:

$$
\begin{aligned}
\text { FPNPV }=-I_{0} \\
+\sum_{i=1}^{T} \quad\left(\left[\operatorname{CI} F_{t}^{l}(a)-\mathrm{CIF}_{t}^{r}(a)\right]-\left[\mathrm{TCOF}_{t}^{l}(a), 1+f_{t}^{r}(a)\right]^{t}\left[1+r_{\text {poss }}+f_{t}^{l}(a)+r_{\text {poss }} f_{t}^{l}(a), 1+r_{\text {poss }}+f_{t}^{r}(a)+r_{\text {poss }} f_{t}^{r}(a)\right]^{-t} \rightarrow\right. \\
\left.\left.\operatorname{FPNPV}=-I_{0}(a)\right]\right) \\
\quad\left[\operatorname{CIF}_{t}^{l}(a)-\operatorname{TCOF}_{t}^{r}(a), \operatorname{CIF}_{t}^{l}(a)-\operatorname{TCOF}_{t}^{l}(a)\right] \\
+\sum_{i=1}^{T}\left[\left(1+f_{t}^{l}(a)\right)^{t},\left(1+f_{t}^{r}(a)\right)^{t}\right] \\
\quad\left[\left(1+r_{\text {poss }}+f_{t}^{r}(a)+r_{\text {poss }} f_{t}^{r}(a)\right)^{-t}, 1+\left(r_{\text {poss }}+f_{t}^{l}(a)+r_{\text {poss }} f_{t}^{l}(a)\right)^{-t}\right]
\end{aligned}
$$

- Next, the operation of multiplication on intervals is applied, depending on the sign of the operation $\mathrm{CIF}_{t}[a]-\mathrm{TCOF}_{t}[a]$.

Operations for Definition 8

Nominal to Real

- $\quad$ The basic formula:

$$
F P N P V=-I_{0}+\sum_{i=1}^{T}\left(C I F_{t}-T C O F_{t}\right)(1+r)^{-t} \rightarrow
$$

- Convert the nominal cash flows and nominal discount rate to real values:

$$
\begin{gathered}
F P N P V=-I_{0}+\sum_{i=1}^{T}\left(C I F_{t}-\text { TCOF }_{t}\right)(1+f)^{-t}\left((1+r)(1+f)^{-1}\right)^{-t} \rightarrow \\
F P N P V=-I_{0}+\sum_{i=1}^{T}\left(C I F_{t}[a]_{t}-T_{C O F}\right)(1+f)^{-t}\left(1+\frac{r-f}{1+f}\right)^{-t} \rightarrow
\end{gathered}
$$

- The extension principle:

$$
\begin{aligned}
& F P N P V=-I_{0} \\
& \begin{array}{l}
+\sum_{i=1}^{T} \quad\left(\left[1+f_{t}^{l}(a), 1+f_{t}^{r}(a)\right]^{t}\left(1+\frac{\left[r_{\text {poss }}-f_{t}^{r}(a), r_{\text {poss }}-f_{t}^{l}(a)\right]}{\left[1+f_{t}^{l}(a), 1+f_{t}^{r}(a)\right]}\right)\right. \\
\text { FPNPV }=-I_{0}
\end{array} \\
& \begin{array}{ll}
+\sum_{i=1}^{T} & \left(\left[\operatorname{CIF}_{t}^{l}(a)-\operatorname{TCOF}_{t}^{r}(a), \operatorname{CIF}_{t}^{l}(a)-f_{t}^{l}(a), 1+f_{t}^{r}(a)\right]^{t}\left[1+\frac{r_{\text {poss }}-f_{t}^{r}(a)}{1+f_{t}^{r}(a)}, 1+\frac{r_{\text {poss }}-f_{t}^{l}(a)}{1+f_{t}^{l}(a)}\right]^{-t}\right.
\end{array}
\end{aligned}
$$

- Next, the operation of multiplication on intervals is applied, depending on the sign of the operation CIF $[a]-\operatorname{TCOF}_{t}[a]$.

Operations for Definition 9

No conversion needed

$$
F P N P V=-I_{0}+\sum_{i=1}^{T}\left(\left(p_{t}-\operatorname{cof} f_{t}\right) x_{t}-C O F_{t}\right)(1+r)^{-t}+L(1+r)^{-T} \rightarrow
$$

- The extension principle:

$$
\begin{aligned}
& F P N P V=-I_{0} \\
& +\sum_{i=1}^{T}\left(\left(\left[p_{t}^{l}(a), p_{t}^{r}(a)\right]-\left[\operatorname{cof}_{t}^{l}(a), \operatorname{cof}_{t}^{r}(a)\right]\right)\left[x_{t}^{l}(a), x_{r}^{r}(a)\right]-\left[\operatorname{COF}_{t}^{l}(a), \operatorname{COF}_{t}^{r}(a)\right]\right) \rightarrow \\
& \left.F P N P V=-I_{0}\right) \\
& \left.+\sum_{t}^{T}(a), L_{t}^{r}(a)\right]\left(1+r_{\text {poss }}\right)^{-T} \\
& \left.\left.+\sum_{i=1}^{T}\left(1+r_{\text {poss }}^{l}(a)-\operatorname{cof}\right)_{t}^{r}(a)\right) x_{t}^{l}(a)-\operatorname{COF}_{t}^{r}(a),\left(p_{t}^{r}(a)-\operatorname{cof}_{t}^{l}(a)\right) x_{t}^{r}(a)-\operatorname{COF}_{t}^{l}(a)\right]
\end{aligned}
$$


- Next, the operation of multiplication on intervals is applied, depending on the sign of the operation $\left(p_{t}[a]-\operatorname{cof} f_{t}[a]\right) x_{t}[a]-\operatorname{COF}_{t}[a]$.

Operations for Definition 10

Real to Nominal

- $\quad$ The basic formula:

$$
F P N P V=-I_{0}+\sum_{i=1}^{T}\left(\left(p_{t}-c o f_{t}\right) x_{t}-C O F_{t}\right)(1+r)^{-t}+L(1+r)^{-T} \rightarrow
$$

- $\quad$ Convert the real cash flows and real discount rate to nominal values:

$$
\begin{aligned}
& F P N P V=-I_{0}+\sum_{i=1}^{T} \begin{array}{ll}
\left(\left(p_{t}-\operatorname{cof} f_{t}\right) x_{t}-C O F_{t}\right)(1+f)^{t}((1+r)(1+f))^{-t}+ \\
L(1+f)^{t}((1+r)(1+f))^{-T}
\end{array} \rightarrow \\
& \begin{array}{ll}
F P N P V=-I_{0}+\sum_{i=1}^{T} \begin{array}{l}
\left(\left(p_{t}-\operatorname{cof}_{t}\right) x_{t}-\mathrm{COF}_{t}\right)(1+f)^{t}(1+r+f+r f)^{-t} \\
+L(1+f)^{t}(1+r+f+r f)^{-T} \rightarrow
\end{array}
\end{array}
\end{aligned}
$$

- The extension principle:

$$
\begin{aligned}
& \text { FPNPV }=-I_{0} \\
&\left(\left(\left[p_{t}^{l}(a), p_{t}^{r}(a)\right]-\left[\operatorname{cof} f_{t}^{l}(a), \operatorname{co} f_{t}^{r}(a)\right]\right)\left[x_{t}^{l}(a), x_{r}^{r}(a)\right]-\left[C O F_{t}^{l}(a), \operatorname{COF}_{t}^{r}(a)\right]\right) \\
&+\sum_{i=1}^{T} \quad {\left[1+f_{t}^{l}(a), 1+f_{t}^{r}(a)\right]^{t}\left[1+r_{\text {poss }}+f_{t}^{l}(a)+r_{\text {poss }} f_{t}^{l}(a), 1+r_{\text {poss }}+f_{t}^{r}(a)+r_{\text {poss }} f_{t}^{r}(a)\right]^{-t} \rightarrow } \\
& {\left[1+r_{\text {poss }}+f_{t}^{l}(a)+r_{\text {poss }} f_{t}^{l}(a), 1+r_{\text {poss }}+f_{t}^{r}(a)+r_{\text {poss }} f_{t}^{r}(a)\right]^{-T} } \\
& \text { FPNPV } {\left[1+I_{0}\right.} \\
& {\left[\left(p_{t}^{l}(a)-\operatorname{cof} f_{t}^{r}(a)\right) x_{t}^{l}(a)-\operatorname{COF}_{t}^{r}(a),\left(p_{t}^{r}(a)-\operatorname{cof} f_{t}^{l}(a)\right) x_{t}^{r}(a)-\operatorname{COF}_{t}^{l}(a)\right] } \\
&+\sum_{i=1}^{T} \quad\left[1+f_{t}^{l}(a), 1+f_{t}^{r}(a)\right]^{t}\left[1+r_{\text {poss }}+f_{t}^{l}(a)+r_{\text {poss }} f_{t}^{l}(a), 1+r_{\text {poss }}+f_{t}^{r}(a)+r_{\text {poss }} f_{t}^{r}(a)\right]^{-t} \\
&+\left[\left[L_{t}^{l}(a), L_{t}^{r}(a)\right]\left[1+f_{t}^{l}(a), 1+f_{t}^{r}(a)\right]\right. \\
& {\left[1+r_{\text {poss }}+f_{t}^{l}(a)+r_{\text {poss }} f_{t}^{l}(a), 1+r_{\text {poss }}+f_{t}^{r}(a)+r_{\text {poss }} f_{t}^{r}(a)\right]^{-T} }
\end{aligned}
$$

- Next, the operation of multiplication on intervals is applied, depending on the sign of the operation $\left(p_{t}[a]-\operatorname{cof}_{t}[a]\right) x_{t}[a]-\operatorname{COF}_{t}[a]$.

Operations for Definition 11

Nominal to Real

- $\quad$ The basic formula:

$$
F P N P V=-I_{0}+\sum_{i=1}^{T}\left(\left(p_{t}-c o f_{t}\right) x_{t}-C O F_{t}\right)(1+r)^{-t}+L(1+r)^{-T} \rightarrow
$$

- Converting nominal cash flows and nominal discount rate to real values:

$$
\begin{aligned}
& \begin{array}{ll}
\text { FPNPV }=-I_{0}+\sum_{i=1}^{T} \begin{array}{l}
\left(\left(p_{t}-\operatorname{cof} f_{t}\right) x_{t}-\mathrm{COF}_{t}\right)(1+f)^{-t}((1+r)(1+f))^{-t} \\
+L(1+f)^{t}((1+r)(1+f))^{-T} \rightarrow
\end{array}
\end{array} \\
& F P N P V=-I_{0}+\sum_{i=1}^{T}\left(\left(p_{t}-c o f_{t}\right) x_{t}-C_{C O F}\right)(1+f)^{-t}\left(1+\frac{r_{p s s}-f}{1+f}\right)^{-t}+L(1+f)^{t}\left(\frac{r_{p o s s}-f}{1+f}\right)^{-T} \rightarrow
\end{aligned}
$$

- The extension principle:

$$
\begin{aligned}
& \text { FPNPV }=-I_{0} \\
& \quad\left(\left(\left[p_{t}^{l}(a), p_{t}^{r}(a)\right]-\left[\operatorname{co} f_{t}^{l}(a), \operatorname{cof}_{t}^{r}(a)\right]\right)\left[x_{t}^{l}(a), x_{r}^{r}(a)\right]-\left[\operatorname{COF}_{t}^{l}(a), \operatorname{COF}_{t}^{r}(a)\right]\right) \\
& +\sum_{i=1}^{T} \quad\left[1+f_{t}^{l}(a), 1+f_{t}^{r}(a)\right]^{t}\left(1+\frac{\left[r_{\text {poss }}-f_{t}^{r}(a), r_{\text {poss }}-f_{t}^{l}(a)\right]}{\left[1+f_{t}^{l}(a), 1+f_{t}^{r}(a)\right]}\right) \\
& \quad+\left[L_{t}^{l}(a), L_{t}^{r}(a)\right]\left[1+f_{t}^{l}(a), 1+f_{t}^{r}(a)\right]\left(1+\frac{\left[r_{\text {poss }}-f_{t}^{r}(a), r_{\text {poss }}-f_{t}^{l}(a)\right]}{\left[1+f_{t}^{l}(a), 1+f_{t}^{r}(a)\right]}\right)
\end{aligned}
$$


- Next, the operation of multiplication on intervals is applied, depending on the sign of the operation $\left(p_{t}[a]-\operatorname{cof} f_{t}[a]\right) x_{t}[a]-\operatorname{COF}_{t}[a]$ :

$$
\begin{aligned}
& \text { FPNPV }=-I_{0} \\
& \quad\left[\left(p_{t}^{l}(a)-\operatorname{cof} f_{t}^{r}(a)\right) x_{t}^{l}(a)-\operatorname{COF}_{t}^{r}(a),\left(p_{t}^{r}(a)-\operatorname{cof} f_{t}^{l}(a)\right) x_{t}^{r}(a)-\operatorname{COF}_{t}^{l}(a)\right] \\
& +\sum_{i=1}^{T} \quad\left[1+f_{t}^{l}(a), 1+f_{t}^{r}(a)\right]^{t}\left[1+\frac{r_{\text {poss }}-f_{t}^{r}(a)}{1+f_{t}^{r}(a)}, 1+\frac{r_{\text {poss }}-f_{t}^{l}(a)}{1+f_{t}^{l}(a)}\right]^{-t} \\
& +\left[L_{t}^{l}(a), L_{t}^{r}(a)\right]\left[1+f_{t}^{l}(a), 1+f_{t}^{r}(a)\right]\left[1+\frac{r_{\text {poss }}-f_{t}^{r}(a)}{1+f_{t}^{r}(a)}, 1+{\left.\frac{r_{\text {poss }}-f_{t}^{l}(a)}{1+f_{t}^{l}(a)}\right]}^{-T}\right.
\end{aligned}
$$

\section{References}

1. Gotze, U.; Northcott, D.; Schuster, P. Investment Appraisal Methods and Models, 2nd ed.; Springer: Berlin/Heidelberg, Germany, 2015.

2. $\quad$ Ross, T.J. Fuzzy Logic with Engineering Applications, 3rd ed.; John Wiley \& Sons Ltd.: Chichester, West Sussex, UK, 2004.

3. Chrysafis, K.A.; Papadopoulos, B.K. Cost-volume-profit analysis under uncertainty: A model with fuzzy estimators based on confidence intervals. Int. J. Prod. Res. 2009, 47, 5977-5999. [CrossRef]

4. Tsao, C.-T. Assessing the probabilistic fuzzy net present value for a capital investment choice using fuzzy arithmetic. J. Chin. Inst. Ind. Eng. 2005, 22, 106-118. [CrossRef]

5. Tsao, C.-T. A fuzzy MCDM approach for stock selection. J. Oper. Res. Soc. 2006, 57, 1341-1352. [CrossRef]

6. Filev, D.P.; Yager, R.R. Learning Celibate Fuzzy Models. Available online: http://www.panix.com/ \{\}yager/HP/pubs.html (accessed on 17 December 2020).

7. Garman, M.B.; Klass, M.J. On the Estimation of Security Price Volatilities from Historical Data. J. Bus. 1980, 53, 67. [CrossRef]

8. Lin, H.-W.; Lu, H.-F. Evaluating the BOT project of sport facility: An application of fuzzy net present value method. J. Ind. Prod. Eng. 2013, 30, 220-229. [CrossRef]

9. Peng, J.-G.; Xia, G. A systematic fuzzy multi-criteria group decision-making approach for alternatives evaluation. J. Oper. Res. Soc. 2019, 70, 1490-1501. [CrossRef]

10. Rogers, L.C.G.; Satchell, S.E.; Yoon, Y. Estimating the volatility of stock prices: A comparison of methods that use high and low prices. Appl. Financ. Econ. 1994, 4, 241-247. [CrossRef]

11. Tsao, C.-T. The expectation-deviation net present value by fuzzy arithmetic for capital investments. J. Stat. Manag. Syst. 2010, 13, 267-281. [CrossRef]

12. Wu, L.-C.; Tsai, I.-C. Three fuzzy goal programming models for index portfolios. J. Oper. Res. Soc. 2014, 65, 1155-1169. [CrossRef]

13. Wong, E.T.T.; Norman, G.; Flanagan, R. A fuzzy stochastic technique for project selection. Constr. Manag. Econ. 2000, 18, 407-414. [CrossRef]

14. Appadoo, S.; Bhatt, S.K.; Bector, C.R. Application of possibility theory to investment decisions. Fuzzy Optim. Decis. Mak. 2008, 7, 35-57. [CrossRef]

15. Appadoo, S.S.; Thavaneswaran, A. Possibilistic moment generating functions of fuzzy numbers with GARCH applications. Adv. Fuzzy Syst. 2010, 6, 33-62.

16. Carlsson, C.; Fullér, R. On possibilistic mean value and variance of fuzzy numbers. Fuzzy Sets Syst. 2001, 122, 315-326. [CrossRef]

17. Muzzioli, S.; Reynaerts, H. American option pricing with imprecise risk-neutral probabilities. Int. J. Approx. Reason. 2008, 49, 140-147. [CrossRef]

18. Muzzioli, S.; Reynaerts, H. The solution of fuzzy linear systems by non-linear programming: A financial application. Eur. J. Oper. Res. 2007, 177, 1218-1231. [CrossRef]

19. Kahraman, C.; İhsan, K. Investment analyses using fuzzy probability concept. Ukio Technol. Ir Ekon. Vystym. 2010, 16, 43-57.

20. Collan, M.; Carlsson, C.; Majlender, P. Fuzzy Black and Scholes Real Options Pricing. J. Decis. Syst. 2003, 12, 391-416. [CrossRef]

21. Tsao, C.-T. Fuzzy net present values for capital investments in an uncertain environment. Comput. Oper. Res. 2012, 39, 1885-1892. [CrossRef]

22. Chrysafis, K.A.; Papadopoulos, B.K. Possibilisic moments for the task duration in Fuzzzy PERT. J. Manag. Eng. 2015, 31, 5. [CrossRef]

23. Chatterjee, K.; Zavadskas, E.K.; Tamošaitienè, J.; Adhikary, K.; Kar, S. A Hybrid MCDM Technique for Risk Management in Construction Projects. Symmetry 2018, 10, 46. [CrossRef]

24. Dahooie, J.H.; Zavadskas, E.K.; Abolhasani, M.; Vanaki, A.; Turskis, Z. A Novel Approach for Evaluation of Projects Using an Interval-Valued Fuzzy Additive Ratio Assessment (ARAS) Method: A Case Study of Oil and Gas Well Drilling Projects. Symmetry 2018, 10, 45. [CrossRef]

25. Gebrehiwet, T.; Luo, H. Risk Level Evaluation on Construction Project Lifecycle Using Fuzzy Comprehensive Evaluation and TOPSIS. Symmetry 2019, 11, 12. [CrossRef]

26. Leśniak, A.; Kubek, D.; Plebankiewicz, E.; Zima, K.; Belniak, S. Fuzzy AHP Application for Supporting Contractors' Bidding Decision. Symmetry 2018, 10, 642. [CrossRef]

27. Rola, P.; Kuchta, D. Application of Fuzzy Sets to the Expert Estimation of Scrum-Based Projects. Symmetry 2019, 11, 1032. [CrossRef] 
28. Boloș, M.-I.; Bradea, I.-A.; Delcea, C. A Fuzzy Logic Algorithm for Optimizing the Investment Decisions within Companies. Symmetry 2019, 11, 186. [CrossRef]

29. Chrysafis, K.A.; Theotokas, I.N.; Lagoudis, I.N. Managing fuel price variability for ship operations via bunkering contracts. In Proceedings of the International Association of Maritime Economists (IAME) Conference, "Sustainable development of shipping and trading", Hong Kong, China, 10-13 June 2020; ID320.

30. Zainol Abidin, S.N.; Jaaman, S.H.; Ismail, M.; Abu Bakar, A.S. Clustering Stock Performance Considering Investor Preferences Using a Fuzzy Inference System. Symmetry 2020, 12, 1148. [CrossRef]

31. Plebankiewicz, E.; Wieczorek, D. Adaptation of a Cost Overrun Risk Prediction Model to the Type of Construction Facility. Symmetry 2020, 12, 1739. [CrossRef]

32. Hanćkowiak, L.A. On Application Oriented Fuzzy Numbers for Imprecise Investment Recommendations. Symmetry 2020, 12, 1672.

33. Zadeh, L.A. Fuzzy Sets. Inf. Control. 1965, 8, 338-353. [CrossRef]

34. Zadeh, L.A. Fuzzy sets as the basis for a theory possibility. Fuzzy Sets Syst. 1978, 1, 3-28. [CrossRef]

35. Klir, G.J.; Yuan, B. Fuzzy Sets and Fuzzy Logic: Theory and Applications; Prentice Hall: Englewood Cliffs, NJ, USA, 1995.

36. Sfiris, D.S.; Papadopoulos, B.K. Non-asymptotic fuzzy estimators based on confidence intervals. Inf. Sci. 2014, 279 , 446-459. [CrossRef]

37. Chrysafis, K.A. Corporate investment appraisal with possibilistic CAPM. Math. Computer Model. 2012, 55, 1041-1050. [CrossRef]

38. Cox, J.C.; Ross, S.A.; Rubinstein, M. Options pricing: A simplified formula. J. Financ. Econ. 1979, 7, 229-263. [CrossRef]

39. Adams, A.T.; Bloomfield, D.S.F.; Booth, P.M.; England, P.D. Investment Mathematics and Statistics; Graham \& Trotman: Cambridge, UK, 1993.

40. Yang, D.; Zhang, Q. Drift-Independent Volatility Estimation Based on High, Low, Open, and Close Prices. J. Bus. 2000, 73, 477-491. [CrossRef] 